\title{
Recurrent Childhood Pineoblastoma
}

National Cancer Institute

\section{Source}

National Cancer Institute. Recurrent Childhood Pineoblastoma. NCI Thesaurus. Code C115374.

The reemergence of pineoblastoma in childhood after a period of remission. 